\title{
ESTUDO DA PRODUÇÃO DE TOMATE EM PÓ POR REFRACTANCE WINDOW E POR LIOFILIZAÇÃO
}

\author{
A. DURIGON ${ }^{1}$, M. F. ZOTARELLI; B. A. M. CARCIOFI ${ }^{1}$ e J. B. LAURINDO ${ }^{1}$ \\ ${ }^{1}$ Universidade Federal de Santa Catarina, Departamento de Engenharia Química e Engenharia de \\ Alimentos \\ E-mail para contato: angelisedurigon@gmail.com
}

\begin{abstract}
RESUMO - O método de secagem por refractance window (RW) é utilizado para obtenção de filmes, flocos e pós alimentícios. Assim, o RW pode ser uma alternativa à atomização, à liofilização e ao drum-drying na produção de tomate em pó. O objetivo deste trabalho foi secar a polpa de tomate por RW e por liofilização e caracterizar os pós quanto à atividade de água, tempo de dispersão em água, solubilidade, cor do pó e do produto reidratado. A secagem por RW foi realizada com a temperatura da água de $95{ }^{\circ} \mathrm{C}$ e espessura de espalhamento da polpa de $2 \mathrm{~mm}$. O tempo de secagem da polpa no RW foi inferior a 20 minutos (umidade final de $0,05 \mathrm{~g} \mathrm{~g}^{-1}$ base seca). Os pós de tomate obtidos em ambos os processos apresentaram atividade de água inferior a 0,3. A solubilidade do pó obtido por RW foi maior $(92,5 \%)$ e o tempo de dispersão menor $(3,5 \mathrm{~s})$ se comparados ao pó liofilizado. A capacidade evaporativa do RW supera $10,5 \mathrm{~kg} \mathrm{~m}^{-2} \mathrm{~h}^{-1}$, indicando que esta técnicaé uma alternativa tecnológica viável para a produção de tomate em pó.
\end{abstract}

\section{INTRODUÇÃO}

O tomate é um fruto bastante apreciado mundialmente, rico em licopeno e vitaminas, sendo consumido principalmente in natura, como ingrediente de molhos e pratos salgados. A produção de alimentos em pó, além de ser uma alternativa de processamento para agregar valor a produtos in natura, pode se ser usada para desenvolver novos produtos e ingredientes convenientes para o uso doméstico e industrial. Muitos processos têm sido utilizados para a produção de alimentos em pó, como a atomização (spray drying), a secagem por tambor (drum drying) e a liofilização. Recentemente, o refractance window (RW) tem ganhado a atenção de pesquisadores, como uma alternativa para a produção de alimentos em pó, em flocos ou na forma de filmes (Nindo e Tang, 2007). Nesse processo de secagem o material a ser seco é espalhado sobre uma esteira de poliéster semitransparente à radiação infravermelha, cuja face inferior está em contato direto com água aquecida. Dessa maneira, o calor necessário para o processo de secagem é fornecido para o produto (na forma de solução ou suspensão) pela água quente, através dos mecanismos de condução e radiação (Abonyi et al., 2002; Nindo e Tang, 2007). O uso desse processo para diferentes polpas de frutas e vegetais tem sido estudado por diversos pesquisadores. Caparino et al. (2012) investigaram a influência de vários processos de secagem, como RW, drum drying, spray drying e liofilização, nas propriedades físicas e na microestrutura da manga em pó. Os autores relataram que a qualidade dos pós de manga produzidos por RW foi comparável à qualidade dos pós de manga liofilizados. 
O objetivo desse trabalho foi investigar a secagem de polpa de tomate por refractance window e liofilização e avaliar os produtos em pó obtidos por ambos os processos quanto à solubilidade, tempo de dispersão em água e cor.

\section{MATERIAL E MÉTODOS}

Os tomates utilizados neste estudo foram da variedade Santa Cruz (Lycopersicon lycopersicum) e foram adquiridos no mercado local da cidade de Florianópolis - SC - Brasil. A seleção das frutas foi realizada pelo grau de maturação, observado por análise visual e pelo teor de sólidos solúveis ( ${ }^{\circ}$ Brix), utilizando um refratômetro manual (Reichert, Model AR200, USA). Foram utilizados tomates totalmente vermelhos e com teor de sólidos solúveis entre 4,2 e 5,0 ${ }^{\circ}$ Brix. As frutas foram lavadas, descascadas manualmente e trituradas em liquidificador ("mixer") doméstico (Arno-Brasil) para obtenção da polpa, que foi peneirada em malha de 16 mesh, a fim de evitar a presença de partículas maiores.

Para a realização dos experimentos de secagem por RW, um equipamento operando em batelada foi construído, utilizando o mesmo princípio do equipamento industrial (Nindo e Tang, 2007). O aparato experimental está representado na Figura 1 e consiste de um reservatório de dimensões $0,8 \mathrm{~m}$ x 0,4 m x 0,05 m, com água quente circulante em seu interior, proveniente de um banho termostático (DIST, modelo Di 921, Brasil). O filme mylar tipo "D" (DuPont, USA) de 0,25 mm de espessura encontra-se fixo na parte superior do reservatório, mantendo sua face inferior em contato com a água quente circulante, enquanto sua face superior serve de suporte para o espalhamento da polpa de tomate. A espessura do filme foi escolhida com base em dados da literatura (Nindo et al., 2003). O monitoramento da temperatura do produto e a da água de circulação do reservatório foi realizado através de termopares conectados a um sistema de aquisição de dados (Agilent, modelo 34970A, Malásia). A temperatura da água circulante foi de $95{ }^{\circ} \mathrm{C}$ e a espessura da camada da polpa foi de 2 $\mathrm{mm}$. O espalhamento da polpa de tomate sobre o filme mylar foi realizado com o auxílio de um espalhador manual (doctor blade), o qual permite o ajuste da espessura do filme através de uma lâmina niveladora. 


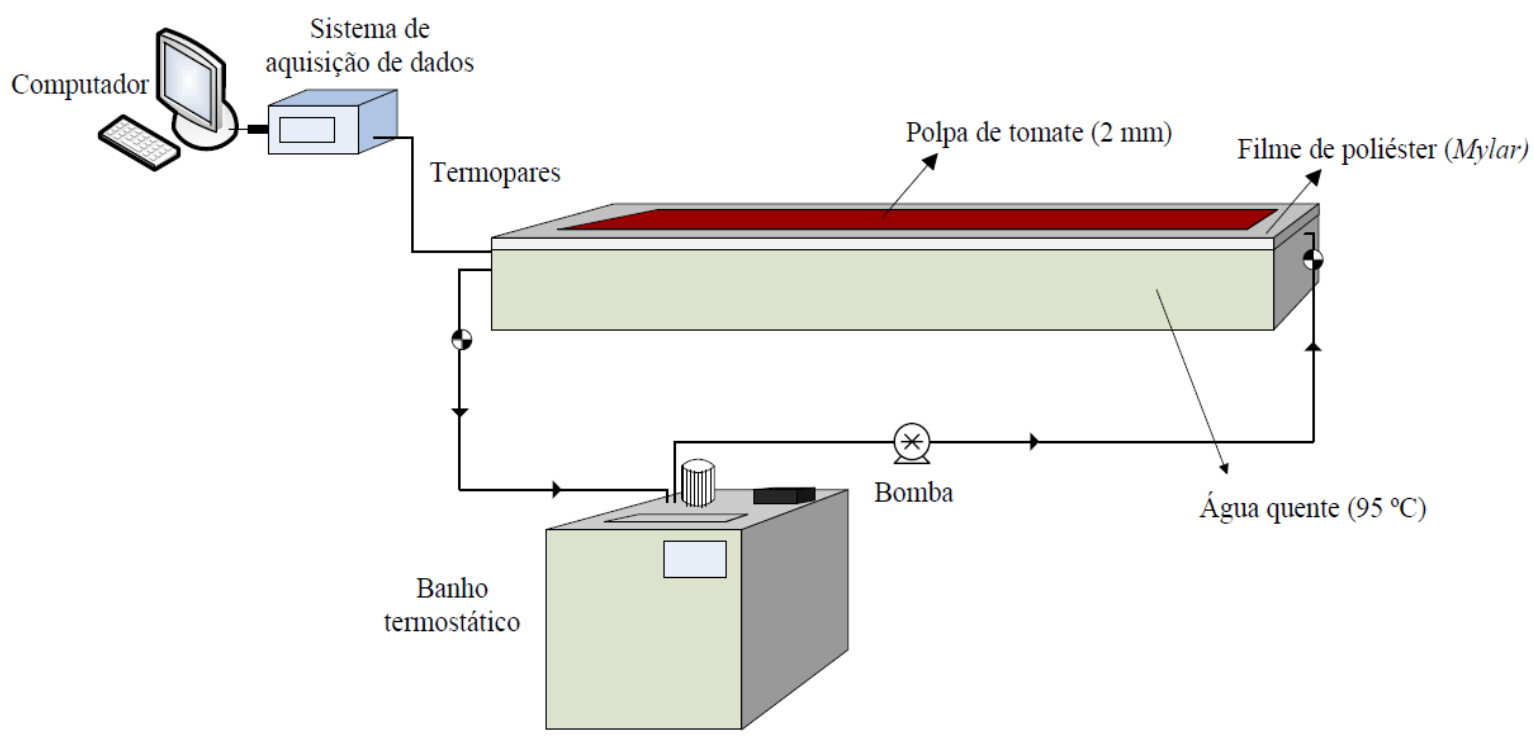

Figura 1 - Aparato experimental do refractance window em batelada.

O processo de secagem da polpa de tomate por liofilização foi realizado em um liofilizador de bancada (Liobrás, Liotop L101, Brasil). As amostras foram colocadas em placas de aço inox com diâmetro interno de $16,5 \mathrm{~cm}$, mantendo-se a espessura da polpa de tomate em aproximadamente 3 $\mathrm{mm}$. Primeiramente, as amostras foram congeladas a $-50^{\circ} \mathrm{C}$ por 12 horas e, após este período, iniciouse a etapa de sublimação, na qual a bomba de vácuo foi acionada e a pressão mantida em $0,04 \mathrm{mmHg}$ até o final do processo de desidratação.

As amostras de tomate desidratadas por RW e por liofilização foram processadas em moinho de facas (TECNAL, modelo TE 631/2, Brasil) para a obtenção de pó desidratado e posterior caracterização quanto à umidade, atividade de água, solubilidade, tempo de dispersão em água e cor. A umidade das amostras foi determinada utilizando o método gravimétrico em estufa a vácuo (TECNAL, TE-395, Brazil) a $70{ }^{\circ} \mathrm{C}$ (A.O.A.C., 2005). A atividade de água $\left(\mathrm{a}_{\mathrm{w}}\right)$ foi determinada em higrômetro digital (Aqualab, Decagon Devices, USA). Para cada experimento as análises de $\mathrm{a}_{\mathrm{w}}$ da polpa e do pó de tomate foram realizadas em triplicata.

A solubilidade (SOL) dos pós de tomate foi determinada segundo o método de Dacanal e Menegalli (2009), com as modificações descritas na sequência. Aproximadamente $1 \mathrm{~g}$ de pó de tomate foi adicionado a um recipiente contendo $100 \mathrm{~mL}$ de água destilada à temperatura de $25^{\circ} \mathrm{C}$, sob agitação, mantendo a altura do vórtice de $30 \mathrm{~mm}$. Após 1 minuto de agitação a solução foi rapidamente filtrada e o filtro, que continha as partículas não dissolvidas, foi seco em estufa com circulação forçada de ar, a $100{ }^{\circ} \mathrm{C}$ durante 24 horas. A solubilidade foi avaliada a partir da fração de material não dissolvido, de acordo com a Equação (1):

$S O L=100-\left[\frac{m_{2}}{m_{1}(1-U B U)} \times 100\right]$ 


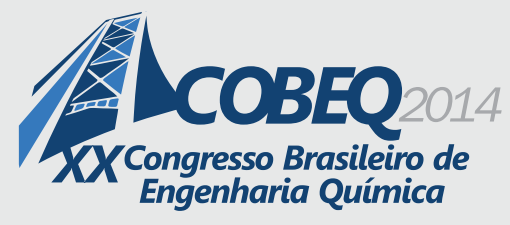

\section{9 a 22 de outubro de 2014 \\ Florianópolis/SC}

em que, $\mathrm{m}_{1}$ é a massa inicial da amostra, $\mathrm{m}_{2}$ é a massa de amostra remanescente no filtro e UBU é a umidade inicial da amostra analisada, em base úmida.

O tempo de dispersão é o tempo necessário para a completa submersão das partículas de pó quando em contato com a superfície de um líquido (Dacanal e Menegalli, 2010) e foi avaliado de acordo com Hogekamp e Schubert (2010). O aparato experimental consiste de um recipiente, preenchido com $80 \mathrm{~mL}$ de água destilada à temperatura de $27{ }^{\circ} \mathrm{C}$, e de um compartimento para a amostra em pó, localizado acima do recipiente que contém o líquido. O reservatório de líquido e o compartimento com o pó são separados por uma lâmina que possui um sistema de acionamento para abertura rápida, por meio de um elástico que a mantém presa na base. Quando o sistema é acionado, o pó ( $1 \mathrm{~g}$ de amostra) entra em contato instantaneamente com a superfície da água, e o tempo necessário para que as partículas fiquem completamente imersas é medido (Hogekamp e Schubert, 2003; Dacanal e Menegalli, 2010).

As medidas de cor do pó de tomate e da polpa reconstituída foram determinadas com o colorímetro (HunterLab, MiniScan EZ 4500L, USA) e a escala utilizada foi a CIELAB. A reidratação foi realizada adicionando água ao pó até a concentração de sólidos solúveis de $25^{\circ}$ Brix. A análise foi realizada em triplicata.

Os resultados de solubilidade, tempo de dispersão e cor foram avaliados pela análise de variância (ANOVA). A comparação múltipla das médias foi realizada pelo uso do teste de Tukey a $10 \%$ de probabilidade de erro $(\mathrm{p}<0,1)$. O processamento dos dados e a análise estatística foram realizados usando o programa estatístico Statistica 8,0 (Statsoft Inc., Tulsa, OK, USA).

\section{RESULTADOS E DISCUSSÃO}

A umidade inicial da polpa de tomate foi de $11,5 \mathrm{~g}$ de água $\mathrm{g}$ de sólidos $\operatorname{secos}^{-1} \mathrm{e}$ a atividade de água 0,999 . O tempo de secagem da polpa por RW foi de 17 minutos e a umidade final do pó foi de $0,03 \mathrm{~g}$ de água $\mathrm{g}$ de sólidos secos ${ }^{-1}$. A taxa de secagem observada nesta condição experimental foi de $1,2 \mathrm{~g} \mathrm{~g}^{-1} \mathrm{~min}^{-1}$ e a capacidade evaporativa do RW foi de $10,5 \mathrm{~kg} \mathrm{~m}^{-2} \mathrm{~h}^{-1}$. A umidade final da polpa de tomate seca por liofilização foi de $0,05 \mathrm{~g}$ de água $\mathrm{g}$ de sólidos $\operatorname{secos}^{-1}$ e o tempo de processo foi de aproximadamente 15 horas. As atividades de água dos pós de tomate secos por RW e por liofilização foram, respectivamente, iguais a 0,265 e 0,298. Na Tabela 1 estão apresentados os valores médios da solubilidade e do tempo de dispersão dos pós de tomate. Segundo Caparino et al. (2012) a solubilidade é o critério mais confiável para avaliar o comportamento do pó na solução aquosa. Conforme os resultados apresentados na Tabela 1 os pós de tomate produzidos por RW apresentaram solubilidade de $92,5 \%$, enquanto a polpa liofilizada apresentou valores de $81 \%$. Abul-Fadl e Ganem (2011) substituíram o poliéster (mylar) por vidro no RW e secaram polpa de tomate com espessura entre 1 e $1,5 \mathrm{~mm}$ e temperatura da água de 60,75 e $90{ }^{\circ} \mathrm{C}$. Os autores verificaram que a umidade final dos pós de tomate foi entre $0,12-0,15 \mathrm{~g}$ de água $\mathrm{g}$ de sólidos $\operatorname{secos}^{-1} \mathrm{e}$ os valores de solubilidade foram em torno de 63,13 e 65,94\%. Os autores justificam que a exposição do produto a temperaturas elevadas por maiores tempos durante o processo de secagem pode reduzir a solubilidade dos 
pós. Para as temperaturas de 60,75 e $90{ }^{\circ} \mathrm{C}$ os tempos de secagem foram de 75,60 e 40 minutos, respectivamente. Caparino et al. (2012) estudaram a secagem de polpa de manga por diferentes processos de secagem, dentre eles o RW e a liofilização. No primeiro processo a temperatura da água foi de $95-97{ }^{\circ} \mathrm{C}$ e a espessura da polpa de 0,5-0,7 $\mathrm{mm}$. Os valores de solubilidade dos pós de manga observados pelos autores foram próximos a $91 \%$ para os pós produzidos por RW e de $90 \%$ para o pó de manga liofilizado.

O tempo de dispersão dos pós de tomate produzidos por RW foi de aproximadamente 3,5 segundo, enquanto os pós produzidos por liofilização apresentaram tempos de 8 segundos

Tabela 1- Solubilidade e tempo de dispersão dos pós de tomate produzidos por refractance window e liofilização.

\begin{tabular}{|c|c|c|c|}
\hline & Amostra & Solubilidade (\%) & Tempo de dispersão (s) \\
\hline \multirow{2}{*}{ Pó } & Refractance Window & $92,58 \pm 1,58^{\mathrm{a}}$ & $3,5 \pm 0,6$ \\
\hline & Liofilizado & $81,14 \pm 3,25^{b}$ & $8,1 \pm 2,7$ \\
\hline
\end{tabular}

Os parâmetros de cor avaliados no pó e na polpa reconstituída de ambos os processos de secagem estão apresentados nas Tabelas 2 e 3, respectivamente.

Tabela 2 - Parâmetros da cor dos pós de tomate produzidos por refractance window e liofilização.

\begin{tabular}{ccccc}
\hline & Amostra & $\mathbf{L}^{*}$ & $\mathbf{a}^{*}$ & $\mathbf{b}^{*}$ \\
\hline \multirow{2}{*}{ Pó } & Refractance Window & $45,53 \pm 0,09^{\mathrm{a}}$ & $30,63 \pm 0,02^{\mathrm{a}}$ & $34,87 \pm 0,02^{\mathrm{a}}$ \\
& Liofilizado & $53,57 \pm 1,09^{\mathrm{b}}$ & $34,60 \pm 0,74^{\mathrm{b}}$ & $25,36 \pm 0,43^{\mathrm{b}}$ \\
\hline
\end{tabular}

a-b Letras iguais na mesma coluna indicam que não há diferença estatística significativa pelo Teste de Tukey $(p \leq 0,10)$.

Tabela 3 - Parâmetros da cor da polpa de tomate reconstituída a partir dos pós secos por refractance window e liofilização.

\begin{tabular}{ccccc}
\hline \multicolumn{2}{c}{ Amostra } & $\mathbf{L}^{*}$ & $\mathbf{a}^{*}$ & $\mathbf{b}^{*}$ \\
\hline \multirow{2}{*}{ Polpa reconstituída } & Refractance Window & $29,49 \pm 0,66^{\mathrm{a}}$ & $26,18 \pm 0,80^{\mathrm{a}}$ & $18,45 \pm 1,16^{\mathrm{a}}$ \\
& Liofilizado & $32,06 \pm 0,60^{\mathrm{b}}$ & $31,55 \pm 0,69^{\mathrm{b}}$ & $16,64 \pm 0,80^{\mathrm{b}}$ \\
\hline \multirow{2}{*}{ a-b Letras iguais na mesma coluna indicam que não há diferença estatística significativa pelo Teste de Tukey $(p \leq 0,10)}$. &
\end{tabular}

De acordo com os resultados, tanto para o pó de tomate quanto para a polpa reconstituída, os parâmetros da cor apresentaram diferença significativa entre os produtos obtidos por ambos os 
processos de secagem avaliados. O pó liofilizado apresentou luminosidade $\left(L^{*}\right)$ mais intensa do que o pó produzido por RW. Devido à coloração vermelha desse fruto, na escala representada por Hunter o parâmetro $a^{*}$ é um dos mais interessantes a ser utilizado para distinção das diferenças de cor resultantes dos processos de secagem. Com base nesse critério, o pó liofilizado apresentou maior valor desse parâmetro. Essa diferença foi observada visualmente, pois o pó produzido por RW apresentou uma coloração tendendo ao marrom. Segundo Porretta (1991) a formação de pigmentos marrons nesse tipo de fruto pode ser proveniente das reações oxidação do ácido ascórbico, condensação de hexoses e compostos de aminas, as quais ocorrem em temperaturas de secagem relativamente altas. Apesar da secagem por RW apresentar um tempo inferior ao da liofilização, o produto permanece exposto a temperaturas mais altas, o que pode favorecer as reações de oxidação.

Com relação à polpa reconstituída, o parâmetro $a^{*}$ também foi mais intenso para o pó liofilizado reidratado. Na Figura 2 estão apresentadas as fotografias das polpas de tomate reconstituídas a partir dos pós secos por ambos os processos.

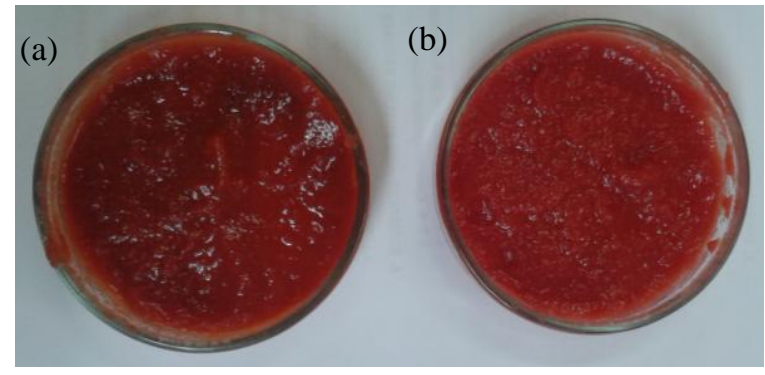

Figura 3 - Polpa de tomate reconstituída a partir do: (a) pó de tomate seco por refractance window e (b) pó de tomate seco por liofilização.

\section{CONCLUSÃO}

A produção de tomate em pó utilizando o refractance window como processo de secagem apresenta-se com o uma alternativa viável à liofilização, visto os tempos reduzidos de processo e a alta capacidade de evaporação desse sistema de secagem nas condições investigadas. O pó produzido por refractance window também apresentou facilidade de reidratação e alta solubilidade em água. Entretanto, a avaliação de cor do pó e do reidratado sugerem a degradação e/ou oxidação de alguns pigmentos durante a secagem por refractance window. Apesar dos baixos tempos desse processo, a exposição do produto à temperaturas relativamente altas pode ter contribuído para a degradação de alguns compostos do produto. Assim, o refractance window apresenta boas perspectivas quanto à sua utilização industrial, competindo com os demais processos de secagem empregados para a produção de alimentos em pó. Entretanto, estudos complementares das condições de processo e da caracterização de produtos secos por essa tecnologia são necessários para consolidar essa tecnologia. 


\section{REFERENCIAS}

ABONYI, B. I., FENG, H., TANG, C. G., EDWARDS, B. P., MATTINSON, D. S., FELLMAN, J. K. Quality retention in strawberry and carrot purees dried with Refractance Window system. J Food Sci., v. 67, p. 1051-1056, 2002.

ABUL-FADL, M. M., GHANEM, T. H. Effect of refractance window drying method on quality criteria of produced tomato powder as compared to the convection drying methotd. World Appl. Sci. J, v. 15, p. 93-96, 2011.

A.O.A.C. ASSOCIATION OF OFFICIAL ANALYTICAL CHEMISTS. Official methods of analysis of Association of Official Analytical Chemists. 18. ed. Maryland, 2005. 1094 p.

CAPARINO, O. A., TANG, J., NINDO, C. I., SABLANI, S. S., POWERS, J. R., FELLMAN, J. K. Effect of drying methods on the physical properties and microstructures of mango (Philippine 'Carabao' var.) powder. J Food Eng., v. 11, p. 135-148, 2012.

GOULA, A. M., ADAMOPOULOS, K. G. Spray drying of tomato pulp in dehumidified air: II. The effect on powder properties. J Food Eng., v. 66, p. 35-42, 2005.

NINDO, C. I.; TANG, J. Refractance Window Dehydration Technology: A Novel Contact Drying Method. Dry. Technol., v. 25, p. 37-48, 2007.

NINDO, C. I., FENG, H., SHEN, G. Q., KANG, D. H. Energy utilization and microbial reduction in a new film drying system. J. Food Process Pres., p. 117-136, 2003.

PORRETA, S. Nonenzimatic browning of tomato products. Food Chem., v. 40, p. 323-335, 1991. 